\title{
Dinâmica da dormência e brotação de gemas de vimeiro no Planalto Sul Catarinense
}

\author{
Tássio Dresch Rech ${ }^{(1)}$, Flávio Zanette ${ }^{(2)}$, Dieter Brandes $^{(1)}$ e Cassandro Vidal Talamini do Amarante ${ }^{(3)}$
}

\begin{abstract}
(1)Empresa de Pesquisa Agropecuária e Extensão Rural de Santa Catarina, Estação Experimental de Lages, Rua João José Godinho, s/no, Bairro Morro do Posto, Caixa Postal 181, CEP 88502-970 Lages, SC. E-mail: tassior@epagri.rct-sc.br, dieterb@brturbo.com (2)Universidade Federal do Paraná, Setor de Ciências Agrárias, Rua dos Funcionários, no 1.540, CEP 80035-050 Curitiba, PR. E-mail: flazan@ufpr.br (3) Universidade do Estado de Santa Catarina, Caixa Postal 281, CEP 88520-000 Lages, SC. E-mail: amarante@cav.udesc.br
\end{abstract}

Resumo - O objetivo deste trabalho foi avaliar a dinâmica e a heterogeneidade de dormência de gemas, e avaliar o efeito de diferentes épocas de colheita de ramos na brotação do vimeiro, no Planalto Sul Catarinense. Ramos de ano foram colhidos nos meses de abril a agosto de 2005, nos municípios catarinenses de Lages, Bocaina do Sul e Urupema. A dormência de gemas foi avaliada em estacas retiradas da base $(0$ a $12 \mathrm{~cm})$, centro $(12$ a $24 \mathrm{~cm})$ e ápice (24 a $36 \mathrm{~cm}$ ) de ramos com comprimento superior a $150 \mathrm{~cm}$. Foram utilizadas estacas com e sem redução para uma única gema. As brotações das plantas em campo também foram avaliadas. A dormência mais intensa de gemas de ramos de ano ocorreu em maio, quando a intensidade de dormência e a freqüência de gemas dormentes decresceram do ápice para a base do segmento basal dos ramos. A colheita do vime em abril induziu a brotação antes do inverno e prejudicou a brotação primaveril.

Termos para indexação: Salix x rubens, heterogeineidade, endodormência, teste de estacas.

\section{Dynamic of dormancy and budburst of willow plants in Planalto Sul, Santa Catarina State, Brazil}

\begin{abstract}
The objective of this work was to evaluate the dynamic and heterogeneity of buds dormancy, and to evaluate the effect of shoot harvest period on willow plant buds breaking in Planalto Sul, Santa Catarina State, Brazil. One-year-old shoots were collected between April and August of 2005 in the counties Lages, Bocaina do $\mathrm{Sul}$, and Urupema. Bud dormancy was evaluated in basal $(0$ to $12 \mathrm{~cm})$, middle (12 to $24 \mathrm{~cm}$ ), and distal (24 to $36 \mathrm{~cm}$ ) cuttings of the shoots. Cuttings with and without reduction to one bud were evaluated. The budburst of willow plants was also evaluated under field conditions. The deepest bud dormancy of basal shoots occurred in May, when the intensity of dormancy and frequency of dormant buds decreased from the top to the bottom of shoots. The harvest of willow shoots in April induced bud break before winter and hampered the budburst in spring.
\end{abstract}

Index terms: Salix x rubens, heterogeneity, endodormancy, cuttings test.

\section{Introdução}

O cultivo do vimeiro no Brasil concentra-se no Planalto Sul Catarinense, onde representa uma das principais fontes de renda na agricultura familiar (Arruda, 2001). A partir da década de 70, o vime passou a ser cultivado nas margens de rios e áreas marginais, com o objetivo de produção de ramos para o artesanato, movelaria e amarrio de parreirais. Somente no final da década de 80 o vimeiro passou a ser cultivado em lavouras sistematizadas. As reclamações mais freqüentes entre os produtores e artesãos são a presença de ramificações nos ramos e a pouca longevidade de algumas lavouras, em relação ao cultivo nas margens dos rios. A presença de ramos laterais aumenta a desuniformidade de diâmetro, favorece o engrossamento e a perda de flexibilidade do vime, além de deixar marcas quando os ramos são removidos após a colheita (Hubbard, 1904). Esses fatores podem estar associados à adaptação da planta ao clima local e às condições de cultivo (Wilson, 2000; Wu \& Hinckley, 2001).

O sistema de cultivo, adotado na região, segue o modelo de colheita de corte rente ao tronco, trazido pelos imigrantes europeus no início do século XX. $\mathrm{O}$ conhecimento da dinâmica de brotação e da heterogeneidade de dormência de gemas possibilita a 
definição de intervenções como a poda, com vistas à orientação de crescimento das plantas, para a produção de ramos com a conformação desejada para o artesanato. Há necessidade, portanto, de mais informações sobre a dormência das gemas, em especial daquelas na base dos ramos, para melhor manejo da poda para a cultura.

A redução do fotoperíodo e a queda das temperaturas são os fatores ambientais fundamentais na indução da evolução da ecodormência (dormência imposta) e da paradormência (inibição correlativa), para a endodormência (dormência de inverno) das gemas (Welling \& Palva, 2006). Salix viminalis L. e $S$. pentandra são espécies sensíveis ao fotoperíodo, pois condições de dias curtos, em ambiente controlado, induzem a parada de crescimento e o aborto das gemas terminais (Barros \& Neill, 1984; Olsen et al., 1997). No entanto, o fotoperíodo reduzido isoladamente não induz a endodormência, uma vez que, em ambiente com temperaturas maiores que $20^{\circ} \mathrm{C}$, o crescimento é retomado assim que a condição de dias longos é restabelecida (Barros \& Neil, 1984).

A entrada da gema em dormência e seus requerimentos em condições de frio são influenciados pelas oscilações e valor absoluto da temperatura, pela quantidade de frio a que foram submetidas, pelas condições nutricionais e hídricas da planta, pelo fotoperíodo, pela irradiância e pela composição espectral da luz (Olsen \& Junttila, 2002; Arora et al., 2003; Welling \& Palva, 2006). À medida que esses fatores produzem diferenças na dinâmica de dormência de gemas do mesmo ramo, determinam a heterogeneidade na dinâmica de entrada de dormência e brotação (Leite, 2004). O estudo da dinâmica da brotação das gemas permite conhecer a influência dos fatores climáticos e de intervenção (poda, desfolha, adubação) sobre a endodormência. $\mathrm{O}$ estudo da heterogeneidade permite compreender a preparação dos arranjos de brotação diferentes nos arbustos e nas árvores (Rageau, 2002).

Um dos testes mais utilizados, para estimar a dormência das gemas, consiste na avaliação da capacidade de crescimento de gemas, isoladas das influências correlativas da planta como um todo, em condições controladas (Dennis, 2003). Zguigal et al. (2006) afirmam que o teste biológico é o único que quantifica a profundidade de dormência e identifica as alterações, promovidas pelo nível de inserção das gemas no ramo e pelas características dos ramos tais como vigor, inclinação e localização do ramo na copa. Uma variação desse método é a utilização de estacas com mais de uma gema, das quais apenas a gema superior é mantida (Citadin et al., 2002; Putti et al., 2003; Carvalho $\&$ Zanette, 2004).

O objetivo deste trabalho foi avaliar a dinâmica e a heterogeneidade de dormência de gemas de ramos, e avaliar o efeito de diferentes épocas de colheita na brotação do vimeiro, no Planalto Sul Catarinense.

\section{Material e Métodos}

$\mathrm{O}$ trabalho foi realizado com ramos de vimeiro (Salix $\mathrm{x}$ rubens Schrank), coletados em três áreas, nos municípios: Lages (913 m de altitude, $27^{\circ} 49^{\prime} \mathrm{S}, 50^{\circ} 19^{\prime} \mathrm{W}$ ), implantadas em 1999, na Empresa de Pesquisa Agropecuária e Extensão Rural de Santa Catarina (Epagri), Estação Experimental de Lages (EELages), SC, com espaçamento de 0,7x1 m; Bocaina do Sul, na localidade de Piúras (852 m de altitude, $27^{\circ} 46$ ' S, $49^{\circ} 52^{\prime} \mathrm{W}$ ), implantada em 2002 , com espaçamento de $0,2 \times 0,7 \mathrm{~m}$; e, Urupema $\left(1.320 \mathrm{~m}\right.$ de altitude, $27^{\circ} 57^{\prime} \mathrm{S}$, $49^{\circ} 52^{\prime} \mathrm{W}$ ), implantada em 1999, com espaçamento de $0,4 \times 0,9 \mathrm{~m}$. As três áreas foram conduzidas em sistema de colheita anual, com corte de todos os ramos rente ao tronco.

$\mathrm{O}$ delineamento foi inteiramente casualizado, em esquema fatorial $3 \times 2$ (estacas retiradas de três posições nos ramos $\mathrm{x}$ estacas com gema única ou estacas com todas as gemas), com parcelas subdivididas no tempo. Cada local (Lages, Urupema e Bocaina do Sul) foi considerado um experimento separado.

As datas de colheita (corte) do vime foram: 18/4/2005, 18/5/2005, 13/6/2005, 11/7/2005 e 8/8/2005 em Urupema; 21/4/2005, 19/5/2005, 16/6/2005, 16/7/2005 e 16/8/2005 em Lages; e 23/5/2005, 15/6/2005, 13/7/2005 e 10/8/2005 em Bocaina do Sul. Em Bocaina do Sul, não foi possível a condução da primeira época de colheita. Dados médios de precipitação $(\mathrm{mm})$ e temperatura $\left({ }^{\circ} \mathrm{C}\right)$ dos três locais de estudo, durante o período de avaliação, são apresentados na Figura 1. Os dados de Lages foram obtidos na EELages da Epagri e no Centro de Informações de Recursos Ambientais e de Hidrometeorologia de Santa Catarina. Os dados de Bocaina do Sul foram obtidos na EELages e com o Sr. Dieter Brandes. Os dados de Urupema foram obtidos na Companhia Integrada de Desenvolvimento Agrícola de Santa Catarina e no escritório local de Urupema da Epagri.

Em cada época de colheita, foram selecionadas dez plantas ao acaso, tendo-se evitado plantas visivelmente 
fracas ou excessivamente vigorosas. Cada planta foi considerada uma repetição. Todos os ramos dessas plantas foram cortados rente ao ponto de inserção no tronco. De cada planta foram selecionados dez ramos com comprimento superior a $150 \mathrm{~cm}$ para a avaliação de dormência, sendo cinco para formar a unidade amostral, que receberia o tratamento estacas com gema única, e cinco para formar a unidade amostral estacas com todas as gemas.

A partir da base do ramo, foram cortados três segmentos de $12 \mathrm{~cm}$, para formar os tratamentos segmento basal, central e distal do ramo. De cada segmento, foram retiradas estacas com $8 \pm 0,3 \mathrm{~cm}$ de comprimento. As estacas foram cortadas a $1 \pm 0,5 \mathrm{~cm}$ acima de uma gema íntegra. Nas estacas referentes ao tratamento gema única, foi mantida a gema distal, e as demais foram removidas. Nos ramos referentes ao tratamento sem remoção de gemas, todas as gemas presentes na estaca foram mantidas.

No mesmo dia da colheita, as estacas foram plantadas em bandejas plásticas de $4 \mathrm{~cm}$ de altura e $10 \mathrm{~cm}$ de raio, contendo uma camada de $3 \mathrm{~cm}$ de
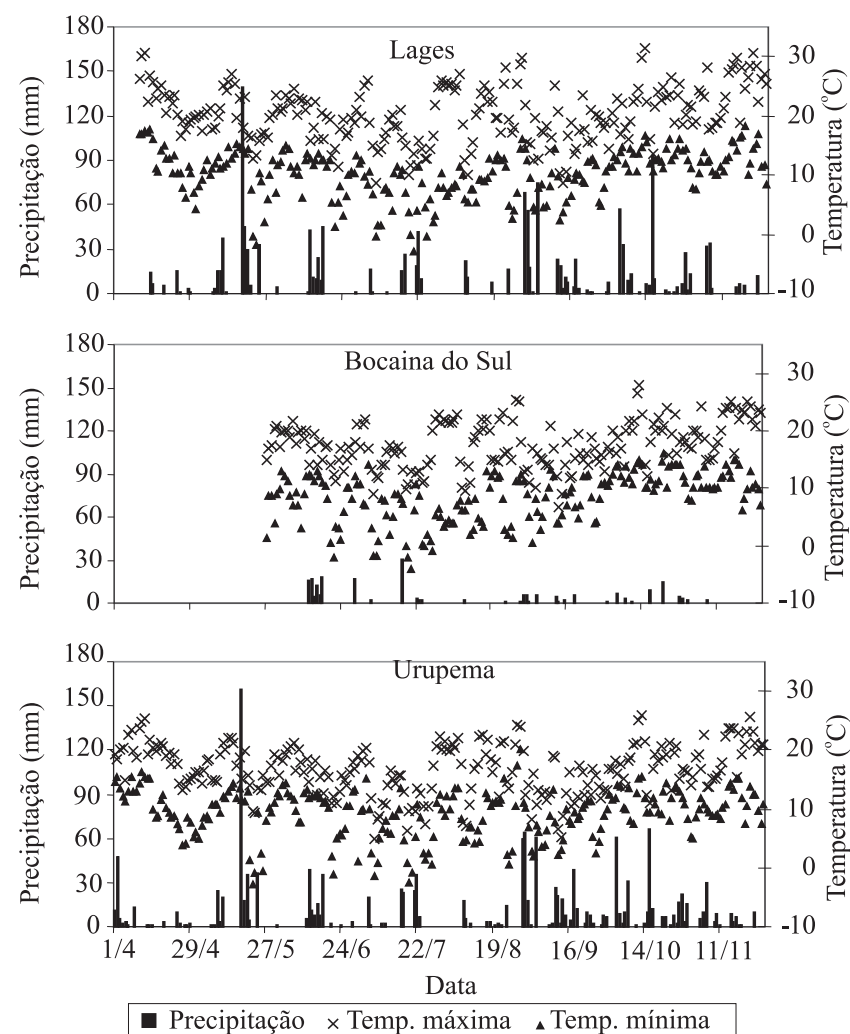

Figura 1. Precipitação e temperatura no período de abril a setembro de 2005, em Lages, Bocaina do Sul e Urupema, SC. vermiculita com granulometria média, umedecida com água destilada. As bandejas foram cobertas com tampas de plástico transparente de $12 \mathrm{~cm}$ de altura, para se evitar a desidratação das estacas, sem impedir a entrada de luz.

As bandejas foram colocadas em sala à temperatura de $24 \pm 2^{\circ} \mathrm{C}$ e umidade relativa do ar de $65 \pm 5 \%$, durante o dia, e $18 \pm 2^{\circ} \mathrm{C}$ e $85 \pm 5 \%$ à noite, com 14 horas de fotoperíodo, e intensidade de radiância diurna de $27,2 \mu \mathrm{mol} \mathrm{m}{ }^{-2} \mathrm{~s}^{-1}$. Foi avaliada a brotação da gema distal de cada estaca. Os brotos oriundos das demais gemas ou mesmo de calos cicatriciais, nos pontos de remoção de gemas, foram anotados e eliminados, para não concorrerem com a brotação da gema distal. As estacas foram consideradas brotadas, quando o segundo entrenó se tornou visível. Este estádio é equivalente à abertura da primeira folha, porém de visualização mais fácil. Algumas vezes, as folhas iniciais dos ramos de vimeiro podem apresentar aspecto retorcido ou assimétrico, mesmo quando adultas. Estacas que não apresentaram brotação após 120 dias, na sala de revelação, foram consideradas dormentes. $\mathrm{O}$ número de dias entre a coleta e a brotação - exposição do segundo entrenó - é denominado tempo para a brotação (TB), e tempo médio para brotação (TMB) é a média dos TB de cada unidade amostral.

Para identificar o ponto de separação entre as gemas dormentes e não dormentes, foram elaborados gráficos com tempos de brotação (TB) ordenados no eixo vertical, e as porcentagens acumuladas do número total de gemas no eixo horizontal, para cada local e segmento de ramo. O ponto de inflexão da curva gerada nos gráficos foi considerado o ponto de dormência, segundo Rech (2006). Gemas com TB inferior ao ponto de inflexão foram consideradas não dormentes, e acima deste ponto, dormentes. Com base nessa separação, foi calculada a frequiência de gemas dormentes (FGD). O cálculo utilizado para a determinação foi: $\mathrm{FGD}=100(\mathrm{nGD} / \mathrm{ntG})$, em que nGD é o número de gemas dormentes e ntG é o número total de gemas avaliadas.

A partir da segunda época, a cada coleta, e de $28 \mathrm{em}$ 28 dias após a última coleta, foi contado o número de brotos presentes nas plantas cortadas nas épocas anteriores até a primeira semana de novembro. Em Urupema, em razão da ausência de brotação nas plantas em que não foram realizadas coletas, no mês de setembro, oito plantas foram cortadas para avaliação 
de rebrote. Em dezembro, foi avaliado o comprimento médio dos ramos de todas as plantas.

Os dados de cada local foram analisados separadamente, para preservar a homogeneidade de variâncias. Para avaliar a normalidade dos dados, foi utilizado o teste de Kolmogorov-Smirnov. A normalização dos dados de TMB foi obtida pela equação trTMB $=1.000 / \mathrm{TMB}$. Os dados de FGD e o número de brotações em campo foram submetidos à transformação Box-Cox (Jonhson \& Wicher, 1998). Os dados foram submetidos a análises de variância, e as médias foram comparadas pelo teste de Tukey, a 5\% de probabilidade.

\section{Resultados e Discussão}

A evolução de brotação das gemas de vimeiros, em Lages, foi semelhante à observada por Rech et al. (2006), com diferenças do TMB (Tabela 1) em resposta à temperatura ambiente (Figura 1); não foi possível identificar o mês de dormência mais profunda. Nesse local, as estacas retiradas da base, centro ou ápice dos ramos de vimeiro não diferiram quanto à profundidade de dormência, calculada pelo TMB. Em Bocaina do Sul e Urupema, a profundidade de dormência foi máxima

Tabela 1. Tempo médio até a brotação (dias), em estacas dos segmentos basal, central e apical de ramos de vimeiro, colhidos entre abril e agosto de 2005, em Lages, Bocaina do Sul e Urupema, $\mathrm{SC}^{(1)}$.

\begin{tabular}{lccc}
\hline Época & \multicolumn{3}{c}{ Segmento } \\
\cline { 2 - 4 } & Basal & Central & Apical \\
\hline & & Lages & \\
Abril & $24,1 \mathrm{Aa}$ & $23,9 \mathrm{Aa}$ & $25,3 \mathrm{Aa}$ \\
Maio & $22,6 \mathrm{ABa}$ & $25,1 \mathrm{Aa}$ & $26,5 \mathrm{Aa}$ \\
Junho & $16,0 \mathrm{ABa}$ & $16,9 \mathrm{ABa}$ & $20,5 \mathrm{ABa}$ \\
Julho & $23,6 \mathrm{ABa}$ & $21,8 \mathrm{ABa}$ & $24,9 \mathrm{Aa}$ \\
Agosto & $13,7 \mathrm{Ba}$ & $13,3 \mathrm{Ba}$ & $13,7 \mathrm{Ba}$ \\
\hline & & Bocaina do Sul & \\
Abril & $-(2)$ & - & - \\
Maio & $28,3 \mathrm{Ab}$ & $36,5 \mathrm{Aab}$ & $53,6 \mathrm{Aa}$ \\
Junho & $21,2 \mathrm{Aa}$ & $23,5 \mathrm{ABa}$ & $25,2 \mathrm{Ba}$ \\
Julho & $23,9 \mathrm{Aa}$ & $26,7 \mathrm{ABa}$ & $27,7 \mathrm{Ba}$ \\
Agosto & $15,7 \mathrm{Aa}$ & $16,3 \mathrm{Ba}$ & $17,0 \mathrm{Ba}$ \\
\hline & & Urupema & \\
Abril & $28,5 \mathrm{ABa}$ & $27,3 \mathrm{Ba}$ & $26,2 \mathrm{Ba}$ \\
Maio & $37,4 \mathrm{Ab}$ & $50,4 \mathrm{Aa}$ & $56,9 \mathrm{Aa}$ \\
Junho & $20,0 \mathrm{Ba}$ & $20,9 \mathrm{Ba}$ & $24,2 \mathrm{Ba}$ \\
Julho & $20,0 \mathrm{Ba}$ & $20,3 \mathrm{Ba}$ & $21,1 \mathrm{Ba}$ \\
Agosto & $18,7 \mathrm{Ba}$ & $18,9 \mathrm{Ba}$ & $18,7 \mathrm{Ba}$ \\
\hline
\end{tabular}

(1)Médias seguidas por letras iguais, em cada local, maiúsculas entre épocas e minúsculas entre segmentos, não diferem entre si pelo teste de Tukey, a 5\% de probabilidade; para as análises estatísticas, os dados foram transformados pela equação trTMB $=1.000 / \mathrm{TMB} .{ }^{(2)}$ Amostragem não realizada. em maio, com maior profundidade para as estacas dos segmentos distais. Isso indica que a heterogeneidade de dormência em ramos de vimeiro, para estacas originárias da base, centro ou ápice de ramos com mais de 1,5 m, possa ser estabelecida em distâncias tão curtas quanto $12 \mathrm{~cm}$, em condições ambientais favoráveis à sua expressão. $\mathrm{O}$ gradiente de profundidade de dormência, observado entre Lages, Bocaina e Urupema, especialmente no mês de maio, pode estar relacionado à influência da temperatura no aprofundamento e reversão da dormência (Barros \& Neil, 1984; Lennartsson \& Ögren, 2002; Welling et al., 2004). Isso pode indicar a insuficiência de frio para o vime, nas condições de Lages.

A diferença na profundidade de dormência, entre os segmentos dos ramos de vimeiro, pode ter importantes implicações no manejo da cultura. Se no caso da maçã, a tendência basítona cria dificuldades de manejo, como discutido por Cook \& Jacobs (1999), para o vime, contrariamente, pode ser vantajosa. A condição de basitonia se caracteriza por brotações mais vigorosas na base do ramo. Nessa condição, a colheita, que atualmente é realizada com corte de todos os ramos rente ao tronco, poderia ser realizada deixando-se parte do ramo, para originar brotações vigorosas no ano seguinte. Entretanto, a uniformidade dos TMBs das gemas basais, centrais e distais, a partir de junho, mesmo nas condições de Bocaina do Sul, pode indicar a reversão precoce da condição basítona. Estudos sobre a interação entre épocas e altura de corte do vimeiro são necessários, uma vez que o caráter basítono pode estar relacionado ao suprimento insuficiente de frio (Cook \& Jacobs, 1999) e ao fotoperíodo (Fustec et al., 2000).

Algumas inferências sobre as exigências em frio podem ser estabelecidas se assumido que a homogeneidade dos TMBs seja um indicativo do restabelecimento da tendência acrotônica, e este como indicativo do suprimento adequado de frio (Cook \& Jacobs, 1999). Em Bocaina do Sul, até a amostragem de agosto, foram observadas 271 horas-frio (HF), e em Urupema, até a colheita de julho, foram observadas 267 HF. Rech et al. (2006) observaram que após 500 HF ocorreu a superação da dormência em Salix x rubens.

A redução do número de gemas das estacas para gema única, nas estacas submetidas ao teste de dormência, não influenciou o tempo de brotação das estacas, o que indica ser esta uma prática desnecessária. 
A freqüência de gemas dormentes (FGD) apresentou interação entre local e época de colheita, e comportamento geral bastante semelhante ao observado para o TMB, o que reflete a interdependência das variáveis (Tabelas 1 e 2). Porém, a distribuição da FGD, diferentemente do TMB, independe do período de avaliação, desde que superior ao ponto de dormência. Isso permite um período de avaliação mais curto, sem a necessidade de critério arbitrário de pré-definição de duração ou de porcentagem de gemas brotadas, apontados por Dennis (2003) como limitantes à capacidade do teste em determinar a profundidade da dormência.

Em Bocaina do Sul e Urupema, foi observada interação entre a época de colheita e os segmentos da parte basal do ramo. Esse fato não foi observado nas estacas colhidas em Lages (Tabela 2). Nos três locais, ocorreu elevação da temperatura, na última semana de junho e na primeira semana de julho. As médias das temperaturas médias, máximas e mínimas, nessas duas semanas, foram respectivamente de $15,3,21,5$ e $10,9^{\circ} \mathrm{C}$ em Lages, de 14,1, 18,7 e $10^{\circ} \mathrm{C}$ em Bocaina do Sul, e de $14,2,18,2$ e $9^{\circ} \mathrm{C}$ em Urupema. Essas condições climáticas parecem ter determinado a reversão da

Tabela 2. Freqüência de gemas dormentes (\%), em estacas dos segmentos basal, central e apical de ramos de vimeiro, colhidos de abril a agosto de 2005, em Lages, Bocaina do Sul e Urupema, SC, em relação à porcentagem acumulada de gemas avaliadas $^{(1)}$.

\begin{tabular}{lrcr}
\hline Época & \multicolumn{3}{c}{ Segmento } \\
\cline { 2 - 4 } & Basal & Central & Distal \\
\hline & & Lages & \\
Abril & $6,1 \mathrm{Ca}$ & $7,0 \mathrm{Ca}$ & $7,1 \mathrm{Ca}$ \\
Maio & $13,0 \mathrm{Ba}$ & $17,0 \mathrm{Ba}$ & $18,0 \mathrm{Ba}$ \\
Junho & $4,0 \mathrm{Ca}$ & $5,0 \mathrm{Ca}$ & $8,0 \mathrm{Ca}$ \\
Julho & $16,0 \mathrm{Aa}$ & $19,2 \mathrm{Aa}$ & $21,0 \mathrm{Aa}$ \\
Agosto & $2,0 \mathrm{Da}$ & $1,0 \mathrm{Da}$ & $0,0 \mathrm{Da}$ \\
\hline & & Bocaina do Sul & \\
Abril & $-(2)$ & - & - \\
Maio & $14,0 \mathrm{Ac}$ & $23,0 \mathrm{Ab}$ & $41,0 \mathrm{Aa}$ \\
Junho & $14,0 \mathrm{Ab}$ & $17,0 \mathrm{Aab}$ & $21,0 \mathrm{Ba}$ \\
Julho & $13,1 \mathrm{Ab}$ & $21,4 \mathrm{Aab}$ & $26,5 \mathrm{ABa}$ \\
Agosto & $0,0 \mathrm{Ba}$ & $0,0 \mathrm{Ba}$ & $0,0 \mathrm{Ca}$ \\
\hline & & Urupema & \\
Abril & $5,3 \mathrm{Ba}$ & $3,0 \mathrm{Ba}$ & $3,3 \mathrm{Ba}$ \\
Maio & $23,0 \mathrm{Ab}$ & $38,0 \mathrm{Aa}$ & $43,0 \mathrm{Aa}$ \\
Junho & $5,0 \mathrm{Ba}$ & $6,0 \mathrm{Ba}$ & $14,0 \mathrm{Ba}$ \\
Julho & $4,0 \mathrm{Ba}$ & $4,0 \mathrm{Ba}$ & $5,0 \mathrm{Ba}$ \\
Agosto & $5,8 \mathrm{Ba}$ & $2,0 \mathrm{Ba}$ & $3,0 \mathrm{Ba}$ \\
\hline
\end{tabular}

(1)Médias seguidas por letras iguais, em cada local, maiúsculas entre épocas e minúsculas entre segmentos, não diferem entre si pelo teste de Tukey, a 5\% de probabilidade; para as análises estatísticas, os dados foram submetidos à transformação Box-Cox (Jonhson \& Wicher, 1998).

${ }^{(2)}$ Amostragem não realizada. dormência em Lages, tendo ocasionado um aumento na FGD em maio e julho, nos três segmentos, e alguma tendência à reversão nos segmentos central e distal em Bocaina do Sul. Esse comportamento foi também observado por Pop et al. (2000) para Salix pulchra. A reversão de dormência é atribuída ao efeito negativo de ciclos curtos de temperaturas moderadamente elevadas, ao processo de quebra de dormência, conforme observado por Erez et al. (1979) em brotos de pêssego. A temperatura e as horas-frio, observadas nas lavouras de vime, estão próximas a valores críticos para a reversão da dormência no vimeiro. Porém, não são suficientemente frias para induzir a dormência de metade das gemas, mesmo em Urupema, local representativo das lavouras de maior altitude da região.

As diferenças climáticas afetaram marcadamente a evolução das brotações, nos três locais (Figura 2). Em Lages e Bocaina do Sul, os vimeiros cortados em abril e em maio apresentaram brotações que foram definhando até a primavera. Nos dois locais, a brotação de outono parece ter prejudicado o vigor e a uniformidade da brotação de primavera e influenciado o comprimento médio dos ramos. As plantas colhidas em julho e agosto, nesses locais, apresentaram brotação abundante a partir de setembro, enquanto as plantas colhidas em abril, maio e junho apresentaram poucos brotos nesse período. Além de não estarem sujeitas à inibição pelos brotos danificados pelo frio, as plantas colhidas em julho e agosto foram estimuladas pelo corte, em momento apropriado à brotação. $\mathrm{O}$ aumento do estímulo à brotação pela injúria ou corte, com a aproximação do final do período de dormência, foi constatado por Paiva \& Robitaille (1978), em ramos de maçã. A brotação mais intensa pode permitir a formação de ramos de vime mais delgados, longos e com menos ramificação, como resultado da competição entre estes. Estas são características muito interessantes na produção de vime para artesanato. As plantas não submetidas à colheita iniciam a brotação no mesmo período que aquelas colhidas em agosto. Portanto, nas condições climáticas de Lages e Bocaina do Sul, o estímulo de corte parece não representar um risco adicional para a colheita de julho e agosto, quanto à possibilidade de geadas tardias.

Em Urupema, as menores temperaturas determinam a ecodormência das gemas, de forma que a brotação só foi observada a partir de setembro, nas plantas submetidas ao corte. Como observado em Bocaina do Sul, também em Urupema as gemas das plantas, colhidas 

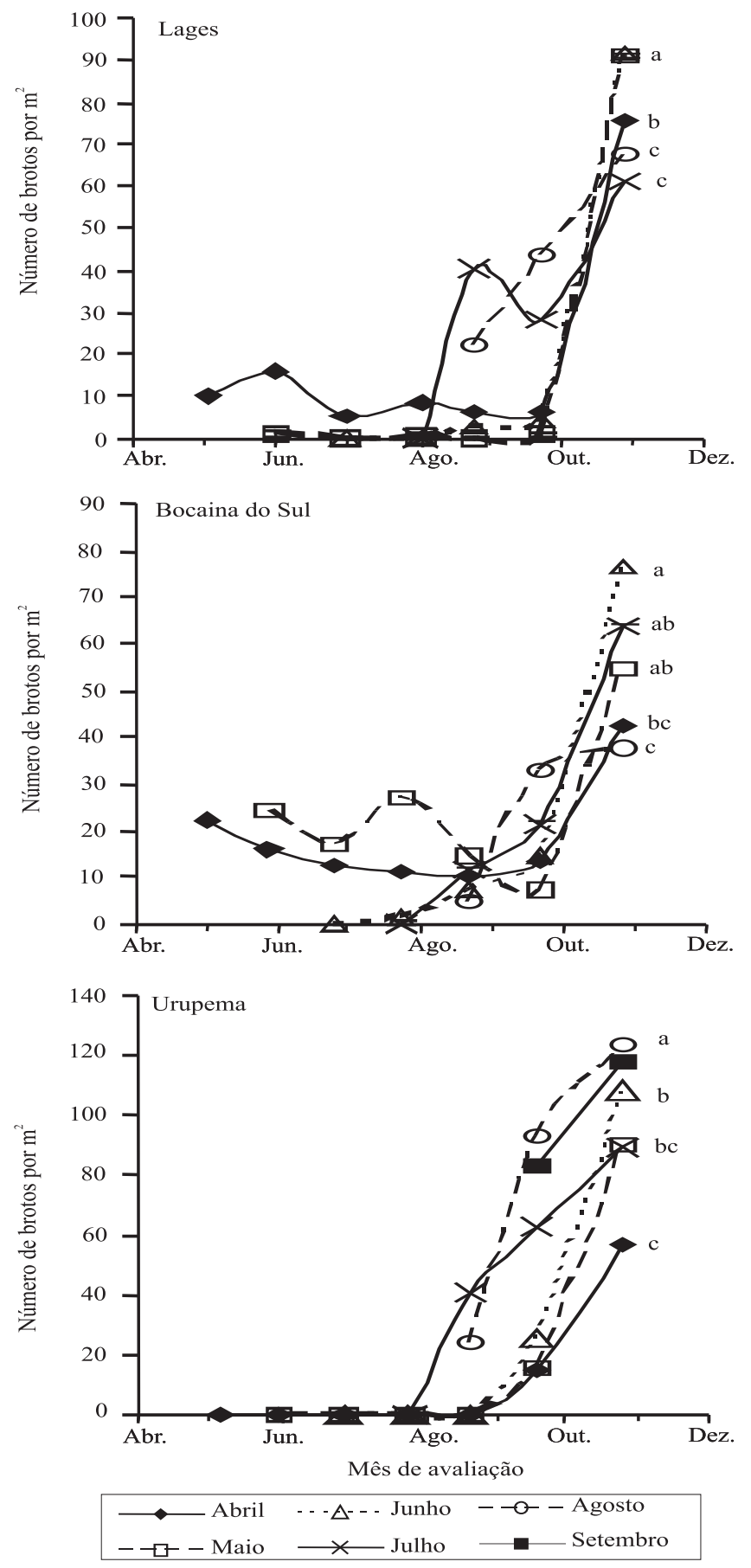

Figura 2. Evolução da brotação de vimeiros colhidos de abril a agosto de 2005 em Lages e Bocaina do Sul, SC, e de abril a setembro, em Urupema, SC. Médias seguidas por letras iguais, na última data de avaliação, não diferem entre si pelo teste Tukey, a 5\% de probabilidade. No mês de setembro a colheita foi feita somente em Urupema, SC. Para as análises estatísticas, os dados foram submetidos à transformação Box-Cox (Jonhson \& Wicher, 1998). em julho e agosto, parecem ainda ter respondido ao estímulo de corte com a emissão de brotos antes das plantas colhidas de abril a junho. Nas condições climáticas de Urupema, a brotação precoce das plantas colhidas em julho pode ser indesejável, pois esses brotos ficam mais expostos à ocorrência de geadas em agosto e setembro, relativamente freqüentes no local, mas que não ocorreram durante o presente trabalho. Em Urupema, o estímulo de corte, promovido pelas colheitas de julho e principalmente de agosto pode ter contribuído não só para a maior precocidade de brotação, mas também para o maior número de brotos (Figura 2). Essa brotação mais abundante ocorreu sem afetar o comprimento médio dos ramos, avaliado em dezembro (Tabela 3).

Em Lages, as brotações mais intensas foram observadas nas plantas colhidas em maio e junho (Figura 2), enquanto os vimeiros cortados em julho e agosto apresentaram brotos mais vigorosos e uniformes, com maior comprimento na avaliação de dezembro (Tabela 3). O maior número de brotos nas colheitas de maio e junho não representa um indicativo de maior produção. De acordo com as observações de campo, essa brotação mais intensa, porém desuniforme, resultou em sombreamento dos brotos menores, que em dezembro estavam amarelados e com gemas terminais abortadas. O abortamento da gema apical é um indicativo claro da paralisação do crescimento, como relatado por Lennartsson \& Ögren (2002), para três espécies do gênero Salix. Além disso, a brotação desuniforme favorece a ramificação dos brotos mais vigorosos. Em Lages, a brotação de primavera das plantas colhidas em abril foi menos abundante (Figura 2) e com brotos menos vigorosos do que a das épocas mais tardias. Essas plantas apresentaram brotação de outono. Muitos desses brotos sobreviveram até a primavera e inibiram a brotação primaveril, que foi uma das mais desuniformes entre as épocas avaliadas.

Tabela 3. Comprimento $(\mathrm{cm})$ médio dos brotos longos de vimeiros, colhidos de abril a agosto de 2005, em Lages, Bocaina do Sul e Urupema, SC, avaliados em dezembro de 2005.

\begin{tabular}{lccc}
\hline Época & Lages & Bocaina do Sul & Urupema \\
\hline Abril & $86,7 \mathrm{~d}$ & $52,2 \mathrm{~b}$ & $113,5 \mathrm{a}$ \\
Maio & $115,0 \mathrm{~cd}$ & $57,8 \mathrm{~b}$ & $115,5 \mathrm{a}$ \\
Junho & $120,2 \mathrm{bc}$ & $71,2 \mathrm{a}$ & $116,4 \mathrm{a}$ \\
Julho & $166,9 \mathrm{ab}$ & $70,6 \mathrm{a}$ & $115,5 \mathrm{a}$ \\
Agosto & $150,2 \mathrm{a}$ & $74,2 \mathrm{a}$ & $119,1 \mathrm{a}$ \\
\hline
\end{tabular}

${ }^{(1)}$ Médias seguidas por letras iguais, em cada local, não diferem entre si pelo teste Tukey, a 5\% de probabilidade. 


\section{Conclusões}

1. A heterogeneidade de dormência de gemas em Salix x rubens, caracterizada pelo decréscimo na freqüência de gemas dormentes do ápice para a base dos ramos, é mais intensa no período de maior profundidade de dormência.

2. O Planalto Sul Catarinense apresenta insuficiência de frio para determinar a entrada em dormência de proporções superiores a $50 \%$ das gemas de qualquer posição de ramos de vimeiro.

3. A colheita de vime antes da entrada em dormência induz a brotação do vimeiro nos períodos favoráveis ao crescimento, durante o inverno, e afeta o vigor, a intensidade e uniformidade de brotação primaveril.

\section{Referências}

ARORA, R.; ROWLAND, L.J.; TANINO, K. Induction and release of bud dormancy in wood perennials: a science comes of age. Horticultural Science, v.38, p.911-921, 2003.

ARRUDA, A.E.A. Importância econômica da cultura do vime para a agricultura familiar de Rio Rufino. 2001.39p. Monografia (Especialização) - Universidade do Oeste de Santa Catarina, São Joaquim.

BARROS, R.S.; NEILL S.J. Effect of chilling on the opening and abscisic acid content of dormant lateral buds of willow. Biologia Plantarum, v.30, p.264-267, 1984.

CARVALHO, R.I.N.; ZANETTE, F. Dinâmica da dormência de gemas de macieira 'Imperial Gala' durante o outono e inverno em região de baixa ocorrência de frio. Revista Brasileira de Fruticultura, v.26, p.65-68, 2004.

CITADIN, I.; RASEIRA, M.C.B.; HERTER, F.G.; SILVEIRA, C.A.P. Avaliação da necessidade em frio de pessegueiro. Revista Brasileira de Fruticultura, v.24, p.703-706, 2002.

COOK, N.C.; JACOBS, G. Suboptimal winter chilling impedes development of acrotony in apple shoots. HortScience, v.34, p.1213-1216, 1999.

DENNIS JUNIOR, F.G. Chilling requirements for the breaking of dormancy in buds of woody plants. HortScience, v.28, p.347-350, 2003.

EREZ, A.; COUVILlON, G.A.; HENDERShOTT, C.H. Quantitative chilling enhancement and negation in peach buds by high temperature in a daily cycle. Journal of the American Society for Horticultural Science, v.104, p.536-540, 1979.

FUSTEC, J.; BEAUJARD, F.; VIÉMONT, J.D.; GENDRAUD, M. Burst potential characterisation by capacity for nucleotide accumulation in Rhododendron catawbiense apical buds. Biologia Plantarum, v.43, p.353-357, 2000.

HUBBARD, W.F. The basket willow. Washington: Government Printing Office, 1904. 100p.

JONHSON, R.A.; WICHERN, D.W. Applied multivariate statistical analysis. Madison: Prentice Hall, 1998. 816p.
LEITE, G.B. Évolution des états des bougeons et de leur hétérogénéité le long du rameau d'un an de pêcher sous différents régimes de temperatures après l'installation de l'endodormance. 2004. 168p. Tese (Doutorado) - Univesité Blaise Pascal, Montpellier.

LENNARTSSON, M.; ÖGREN, E. Causes of variation in cold hardness among fast-growing willows (Salix spp.) with particular reference to their inherent rates of cold hardening. Plant, Cell and Environment, v.25, p.1279-1288, 2002.

OLSEN, J.E.; JUNTTILA, O. Far red end-of-day treatment restores wild type-like plant length in hybrid aspen overexpressing phytochrome A. Physiologia Plantarum, v.115, p.448-457, 2002.

OLSEN, J.E.; JUNTTILA, O.; MORITZ, T. Long-day induced bud break in Salix pentandra is associated with transiently elevated levels of GA1 and gradual increase in indole-3-acetic acid. Plant and Cell Physiology, v.38, p.536-540, 1997.

PAIVA, E.; ROBITAILLE, H.A. Breaking bud rest in detached apple shoots: effects of wounding and ethylene. Journal of the American Society for Horticultural Science, v.103, p.101-104, 1978.

POP, E.W.; OBERBAUER, S.F.; STARR, G. Predicting vegetative bud break in two arctic deciduous shrub species, Salix pulchra and Betula nana. Oecologia, v.124, p.176-184, 2000.

PUTTI, L.P.; PETRI, J.L.; MENDEZ, M.E. Efeito da intensidade do frio no tempo e percentagem de gemas brotadas em macieira. Revista Brasileira de Fruticultura, v.25, p.199-202, 2003.

RAGEAU, R. Dormance des espèces fruitières de climat tempéré: nouveaux concepts. In: ENCONTRO NACIONAL SOBRE FRUTICULTURA DE CLIMA TEMPERADO, 5., 2002, Fraiburgo. Anais. Caçador: EPAGRI, 2002. p.185-201.

RECH, T.D. Ramificação e produtividade do vimeiro em diferentes condições ambientais e de manejo no Planalto Sul Catarinense. 2006. 147p. Tese (Doutorado) - Universidade Federal do Paraná, Curitiba.

RECH, T.D.; ZANETTE, F.; BRANDES, D.; AMARANTE, C.; CABEL, S.R. Requerimento em frio, dinâmica e heterogeneidade de dormência de gemas em ramos de Salix x rubens cultivado em Lages, SC. Ciência Florestal, v.16, p.427-435, 2006.

WELLING, A.; PALVA, E.T. Molecular control of cold acclimation in trees. Physiologia Plantarum, v.127, p.167-181, 2006.

WELLING, A.; RINNE, P.; VIHERÄ-AARNIO, A.; KONTUNENSOPPELA, S.; HEINO, P.; PALVA, E.T. Photoperiod and temperature differentially regulate the expression of two dehydrin genes during overwintering of birch (Betula pubescens Ehrh.). Journal of Experimental Botany, v.55, p.507-516, 2004.

WILSON, B.F. Apical control of branch growth and angle in woody plants. American Journal of Botany, v.87, p 601-607, 2000.

WU, R.; HINCKLEY, T.M. Phenotypic plasticity of sylleptic branching: genetic design of tree architecture. Critical Reviews in Plant Sciences, v.20, p.467-485, 2001.

ZGUIGAL, A.; CHAHBAR, A.; LOUDIYI, D.M.W.; CRABBÉ, J. Caractéristiques de la dormance des bourgeons du pommier dans les régions à hiver doux. Biotechnology, Agronomy, Society and Environment, v.10, p.131-137, 2006. 